\title{
Evaluation of The Use of Building Performance Simulation For Architectural Design Studio Projects
}

\author{
Veronica Soebarto \\ The University of Adelaide, Adelaide, Australia
}

\begin{abstract}
At The University of Adelaide building performance simulation (BPS) has been taught to architecture students, both at the undergraduate and postgraduate levels, for the last 20 years. BPS is taught in an environmental technology course that links to an architectural design course or studio. The main reason for introducing BPS this way, rather than as an independent course separated from the design studio, is to demonstrate to students the important role BPS plays in a design process.

This paper focuses on the experience in learning and teaching BPS at the postgraduate level to assist students in designing mixed-use multi-storey buildings. The paper discusses the structure of the course, the learning/teaching methods, an example of student projects, as well as evaluation by students. Student evaluation includes quantitative evaluation based on Likert Scale and qualitative comments. Lessons learned from this experience will be summarized.
\end{abstract}

\section{Introduction}

It is well understood that architects, as well as other professionals responsible for the design, delivery, and operation of buildings, play significant roles in minimizing the adverse impacts of buildings on the environment and health of the occupants. In the last 20 years, BPS has been taught in an architecture program at The University of Adelaide in South Australia, and since 6 years ago, BPS has been taught as part of a compulsory course in both the undergraduate and postgraduate programs in architecture. Teaching BPS in an architecture program is not new; it aligns with previous studies suggesting that in order to foster the use of BPS in architectural practices, BPS needs to be integrated with design studio teaching (e.g. Charles and Thomas, 2010). However, not all architecture schools teach BPS as part of a compulsory subject even though a previous international survey conducted in the US, UK, Australia and India recommended that BPS be taught as a compulsory subject in tertiary education of architecture (Soebarto et al, 2015). The follow-up survey of the latter study showed that only $50 \%$ of the respondents (or 30 architecture programs) indicated that BPS was taught as a compulsory subject (Hopfe et al, 2017).

In many architecture programs, BPS is often used to understand and analyse the impact of design decisions on the building energy use. Reinhart et al (2012), for example, introduced BPS as a "game" activity with a goal to reduce the simulated Energy Use Intensity (EUI) of an office building. In their approach, a team of 'simulation experts' conducted the simulations while the students were not asked to carry out the simulation themselves. The researchers argued this was not only to save time, but also due to the fact that, in practice architects did not typically conduct simulation. Students made the design decisions and then placed their 'orders' to the simulation experts to carry out the simulation.

Quite the opposite of the above approach, at The University of Adelaide the focus is on directly exposing students to BPS so that they themselves will be able to explore design strategies and simultaneously see the impact of their decisions on the building performance. Rather than solely focusing on reducing the EUI, the emphasis is on achieving thermally comfortable spaces without the use of heating and cooling - in a 'freerunning' mode - as much as possible. In other words, while reducing energy use is an inevitable goal, the main focus is on analysing indoor thermal comfort. Reducing lighting energy through incorporating daylighting as well as ensuring that daylight can reach relevant indoor spaces as much as possible is also emphasised. Both issues of achieving a certain level of thermal and visual comforts as well as reducing energy use are indeed critical in the context of assessing the overall environmental performance of a building.

Until 2018, the IES VE for Architects program (Integrated Environmental Solutions 2011-2019) was used due to its graphical interface, found to be adequate for architecture students, and its claimed capability to import models done in CAD packages such as SketchUp and Revit. Students used the program to explore the impact of building shape, volume and orientation; envelope materials; opening size, location, position and operation; external and internal shading strategies, as well as building operational schedules, on indoor thermal comfort, energy use, and internal daylight. They used reference values, such as ASHRAE adaptive thermal comfort model in ASHRAE 55 (2013) and energy use target relevant to the location to judge their design decisions. In addition, environmental performance assessment tools, such as LEED, BREEAM and Green Star were introduced, and students were to conduct partial assessments of their design using one of these assessment tools, particularly to rate the indoor environmental quality and energy use. 
This paper will discuss the program and course structures as well as the course delivery and show case a student work as an example. It will also discuss student evaluation of using BPS and of the learning experience in general, as well as the learning outcomes. Both the advantages and problems in using BPS during a design process will be particularly highlighted.

\section{Program and course structures}

\section{Program structure}

In this school of architecture, BPS is first introduced in the second year of the 3-year undergraduate level. Students first use BPS to analyse the indoor environmental performance of an existing, small building (usually residential). They then use BPS to investigate the impact of making design changes on the indoor thermal comfort. Only when indoor thermal comfort, with boundaries specified by the adaptive thermal comfort model according to ASHRAE 55 (ASHRAE, 2013) cannot be achieved for more than $90 \%$ of the time by implementing "passive" design strategies, can students propose using some kind of heating and cooling in the building. The design changes to be explored include window shading and glazing, envelope materials, insulation, thermal mass, and natural ventilation. However, since the building is existing, no change of the building orientation can be proposed although as an exercise, students can make changes on the building orientation, to explore the relationship between building location, orientation and indoor comfort. If heating or cooling is applied, the total heating and cooling energy use must not exceed the maximum allowable amount, as determined by the relevant energy efficiency provision of the building code.

In the postgraduate program, BPS is re-introduced in an architectural technologies course for the second year of the Master of Architecture program. The course accounts for $25 \%$ of the semester load, and is taken in conjunction with an architecture design studio. The studio focuses on designing multi-storey mixed-use buildings in an urban context. Typically, the building will have retail spaces on the ground and lower levels, office spaces on the levels above them, and residential spaces (apartments and/or hotels) on the upper floors. Typically, there are around 80 students enrolled in this course.

While the issues addressed in the design studio range from planning, feasibility study, site analysis, historical and cultural contexts, as well as project costs, much emphasis is placed on minimizing the environmental impact of the design, making the use of BPS in the design process very relevant. It is acknowledged that, as argued by Reinhart et al (2012), it is unlikely that in practice an architect of a building of this size will be able to perform BPS during the design process. However, exposing students at this level in their architecture education to BPS allows them to be confident yet critical about their own design decisions rather than simply speculating (that their design "will work"). This premise aligns with an argument by Rauen (2001), even though their focus was on clinical educations, that simulation teaches critical thinking.

\section{Course structure}

As this paper focuses on BPS in the postgraduate program, the course structure discussed here is of this program only.

This is a 12-week course, with one hour of lecture and two hours of tutorial or computer workshops per week. Due to space and time constraints, BPS is only taught for 4 weeks, during weeks 8 to 11 . It is worth pointing out that prior to 2018, BPS was taught earlier in the semester during weeks 4 to 7; however, this structure proved to be challenging. While the idea of introducing BPS early was so that students could explore their design strategies as early as possible during the design process, we found that they used BPS superficially (i.e. to simply receive marks or grades for their work). This was because during those earlier weeks, they still had not had any concrete design that they could test or explore with BPS as they were still in the planning and feasibility study stages. After they had completed the assignment of using BPS to explore design ideas and changes in this architectural technologies course, we found that many students ignored the results and their final design in the studio had no relationship with the simulations they had done earlier. Based on this earlier experience, since 2017, BPS has been introduced during later weeks in the semester after students have progressed their design into the design development stage. This may not be an ideal approach; however, this timing proves to produce much better outcomes.

The course is basically divided into three stages. During the first stage (weeks 1-4), while students are in the planning and concept stage in their design studio course, they are exposed to topics such as "green" design, zero energy and zero carbon (multi-storey) buildings. Their first assignment is to examine and graphically analyse selected case study buildings from around the world, claimed to be "green", "sustainable" and/or zero energy/carbon. During the lecture sessions, various environmental design strategies and technologies, applicable for multi-storey mixed used buildings, are explored.

During the second stage (weeks 5-7), most students will have developed their design concept into a more concrete preliminary design. Thus, during these three weeks students have to develop their environmental design strategies, based on the lessons they have learned during the first four weeks of the course. They develop and explore, conceptually, relevant strategies, so that the spaces in the building will potentially be thermally comfortable without the use, or with minimal use, of heating and cooling, and receive sufficient amount of daylight. These form the second assignment. Note that

while the focus during this stage is on "passive design" strategies applicable to such buildings, active heating and cooling systems are also explored during lectures, and so are issues around indoor air quality and material finishes.

Finally, BPS is introduced in week 8 and further design explorations using BPS are conducted during the subsequent weeks. It is important to mention that, as this is a postgraduate program course, it is assumed that 
students will have had sufficient knowledge about building physics, which is necessary in understanding the fundamentals behind BPS, as we teach building physics in the undergraduate program. Thus, unlike in the undergraduate level, where building physics are explored for 6 weeks prior to teaching BPS, in this course there is no in-depth building physics lectures prior to teaching BPS. However, students are referred back to the building physics notes provided in the undergraduate program, which include topics around climate and weather, thermal comfort, heat transfers through building envelope, heat loss/gain calculations and energy use in buildings.

The final assignment is a demonstration on how students have used BPS to improve the indoor thermal and daylight performance of the building they design in the studio. Students are to present the initial design and any design changes that they have explored to improve the building design. In case of using heating and cooling to improve thermal comfort in the building, they also need to present the predicted energy use of the initial design and that of design changes. In addition, they also present the potential energy and indoor environmental quality scores that they could obtain from an environmental rating system, such as Green Star.

The basic structure of the course is presented in Figure 1.

\begin{tabular}{|c|c|c|}
\hline WEEK & LECTURE & TUTORIAL/WORKSHOP \\
\hline $\begin{array}{l}\text { Week } 1 \\
1 \text { March }\end{array}$ & $\begin{array}{l}\text { Overview: Green, } \\
\text { Sustainable, Zero Buildings }\end{array}$ & Discussion - Assignment 1 \\
\hline $\begin{array}{l}\text { Week } 2 \\
8 \text { March }\end{array}$ & Case Study & Site visit (tbc) \\
\hline $\begin{array}{l}\text { Week } 3 \\
15 \text { March }\end{array}$ & $\begin{array}{l}\text { Design strategies, siting, } \\
\text { zoning, form, materials }\end{array}$ & Discussion of assignment 1 \\
\hline $\begin{array}{l}\text { Week } 4 \\
22 \text { March }\end{array}$ & $\begin{array}{l}\text { 'Passive heating', cooling, } \\
\text { ventilation }\end{array}$ & Presentation of assignment 1 \\
\hline $\begin{array}{l}\text { Week } 5 \\
29 \text { March }\end{array}$ & Active heating and cooling & Consultation \\
\hline $\begin{array}{l}\text { Week } 6 \\
19 \mathrm{Apr}\end{array}$ & Case Study & Discussion of assignment 2 \\
\hline $\begin{array}{l}\text { Week } 7 \\
26 \text { Apr }\end{array}$ & Indoor Air Quality, finishes & Presentation of assignment 2 \\
\hline $\begin{array}{l}\text { Week } 8 \\
3 \text { May }\end{array}$ & $\begin{array}{l}\text { Introduction to Building } \\
\text { Performance Simulation }\end{array}$ & Simulation workshop 1 \\
\hline $\begin{array}{l}\text { Week } 9 \\
10 \text { May }\end{array}$ & Lighting and daylighting & Simulation workshop 2 \\
\hline $\begin{array}{l}\text { Week } 10 \\
17 \text { May }\end{array}$ & $\begin{array}{l}\text { Water and Waste } \\
\text { On-site energy generation }\end{array}$ & Simulation workshop 3 \\
\hline $\begin{array}{l}\text { Week } 11 \\
24 \text { May }\end{array}$ & Environmental assessment & Simulation workshop 4 \\
\hline $\begin{array}{l}\text { Week } 12 \\
31 \text { May }\end{array}$ & Summary & Presentation of Assignment 3 \\
\hline
\end{tabular}

Figure 1: Course structure.

\section{Learning/teaching methods}

An experienced BPS user and researcher teaches the BPS software in a computer lab setting. Two tutors are also present to support students who require one-on-one occasional help. While various on-line tutorial materials and videos exist, the instructor/teacher has also created workshop materials and videos specifically tailored for the course.

The structure of the BPS teaching is as follows:

- Introduction to BPS and the BPS software

- Workshop 1: building geometry and shading

- Workshop 2: materials, use profiles, window opening and simulation

- Workshop 3: heating and cooling, daylighting and simulation

- Workshop 4: natural ventilation and demonstration of CFD

- Help sessions to individual students to model and simulate their own building.

During Workshop 1, the instructor/teacher leads students to create a geometrical model of the building using the BPS software. Students also explore the various features of the software. Due to limited time, usually by the end of the first workshop most students are unable to complete the entire model of the building. Therefore, at the end of the session, a complete model, usually of 4-storey hypothetical office building, located in the same site as the one used in the design studio, will be provided to students so that they can explore the program in their own time after the workshop. Figure 2 shows the basic model that was used in 2018

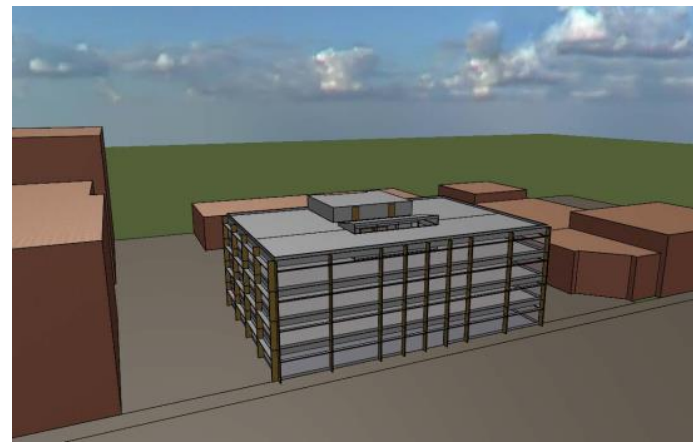

Figure 2: Basic building model used in 2018 to introduce BPS.

In the second and third workshops, students continue to use the same model to explore the topics, as mentioned above. When a topic is presented and discussed, for example on how to model building materials, the impact of using another material is tested immediately by asking students to run the simulation and compare the initial indoor operative temperatures during a peak period in summer or winter, to those of the changed design. This way students will be able to immediately see the impact of building design, no matter how simple the design alteration is, on the building performance.

Due to limited time available to teach BPS, during the third week, students need to start modelling their own building design. Students who use Revit or SketchUp to model their building usually prefer to use the importing capability of the BPS software and import their Revit or SketchUp model into the BPS program. Unfortunately, many students find this process time-consuming and not 
error-free. More often than not, converting a Revit or SketchUp model into the BPS program results in a building model with missing walls or windows, which means the model cannot be simulated. Such problem is not unusual and often occurs during the importing process from a building information model (BIM) or CAD model into a BPS model. Hyun, Marjanovic-Halburd, Raslan (2015) have summarised that this problem is due to different approaches in modelling the building zones in BIM and BPS programs, differences in the data format of the two programs, and different information required.

To save time and avoid the above problems, most students directly model the building in the BPS software. The challenge, however, is on modelling a complex building, particularly one with curved walls or roof or other complex shapes. When this is the case, as the intention of the exercise is to first and foremost improve the thermal and daylight performance of certain spaces rather than looking at the whole building energy use, they will be advised to only model parts of the building that are relevant to be explored. If modelling curved walls or roof proves to be too time consuming, students will be advised to model the curved walls or roof into segments of straight surfaces, as the simulation results of such simplification will be not be significantly different.

After the fourth workshop, students have the opportunity to show to the tutors the initial design and alterations as well as the simulation results during one-on-one tutorials. The course instructor and tutors also check the simulation inputs to ensure that they simulate the buildings correctly. Students are then present their completed work in the final week of the semester.

\section{Example}

Below is an example of student work. The brief was to design a multi-storey mixed-use building in Adelaide $\mathrm{CBD}\left(34.9^{\circ} \mathrm{SL}, 138.6^{\circ} \mathrm{EL}\right)$, consisting of retail spaces on the ground floor, medical offices and clinics on the next three floors, and serviced apartment units in the tower part of the building. The student presented his environmental design concepts, ideas and approaches, such as the building massing, shape and orientation, and ideas for shading and natural ventilation for the apartment units. Although the first goal was to design spaces that would be thermally comfortable without the use, or with minimal use, of heating and cooling, realistically for a building of this size and height, he also had to explore the use of a centralised heating/cooling system. See Figures 3-5.
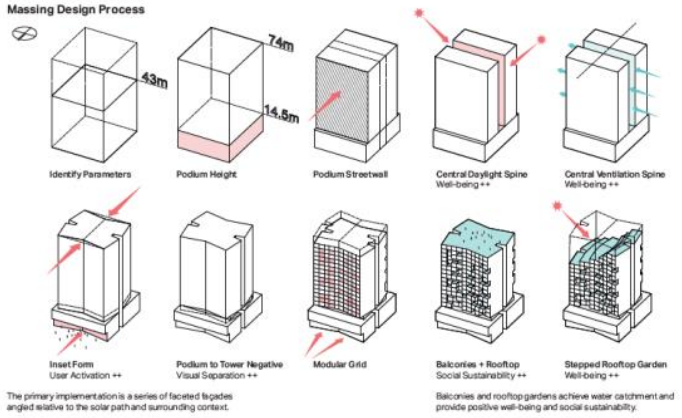

Figure 3: Exploration of building geometry.

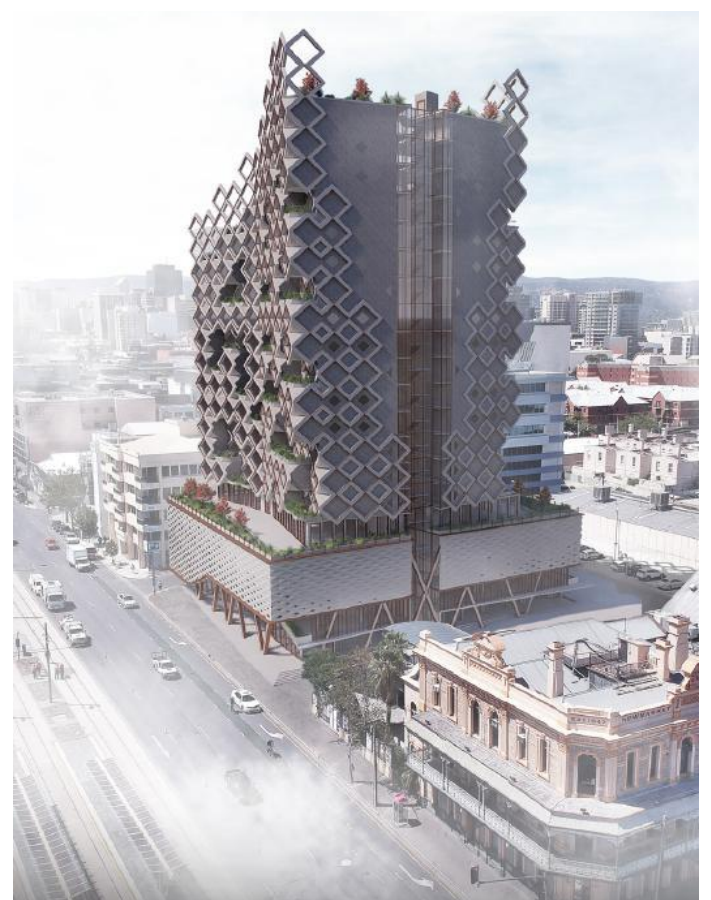

Figure 4: Developed design of the whole building.

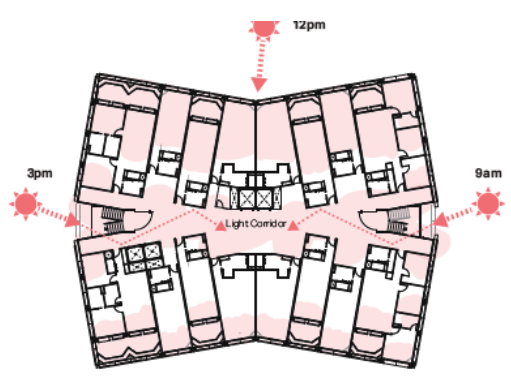

Figure 5: Estimating daylight penetration.

In this city, commercial and apartment buildings contributed to around $48 \%$ of the total $\mathrm{CO} 2$ emission (Government of South Australia, 2015) and most of this was due to the use of air-conditioning and lighting. Therefore, in the third stage of the course, students used a BPS tool (IES) to test the performance of the building they designed in their design studio and attempted to minimize the dependent upon air-conditioning and electric lighting in order to reduce energy use and greenhouse gas emissions from the building.

In this example, the student explored the following design parameters, focusing on the fourth level of the building (Figure 6) as well as one of the apartment levels:

(1) Glazing type

(2) Application of double skin

(3) Change of wall materials

While a building such as this would normally use (centralized) heating and cooling systems, the student first tested the impact of design alterations only on the indoor temperatures without the use of heating and cooling. This was based on the assumption that if relatively comfortable indoor temperatures, as recommended by the adaptive 
model in ASHRAE 55, could be achieved for most of the time without heating and cooling, the building would use little heating and cooling energy, thus minimizing $\mathrm{CO} 2$ emissions.

\section{Stage 1 - Glazing assessment}

As the windows contributed most of the heat gains and losses in the building, the student explored the impact of using different types of glazing: single, double, double low-e with argon infill, and triple low-e with argon infill, on the indoor temperatures when no heating and cooling were in operation. The exploration only focused on two months: February, when the highest summer temperatures usually occurred in this place, and July, when the lowest winter temperatures occurred. Note that in these explorations, all windows were assumed to be closed.

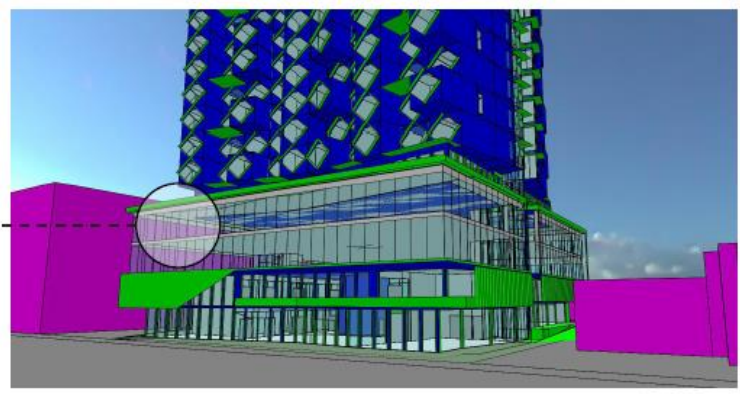

Figure 6: Focused area for study.

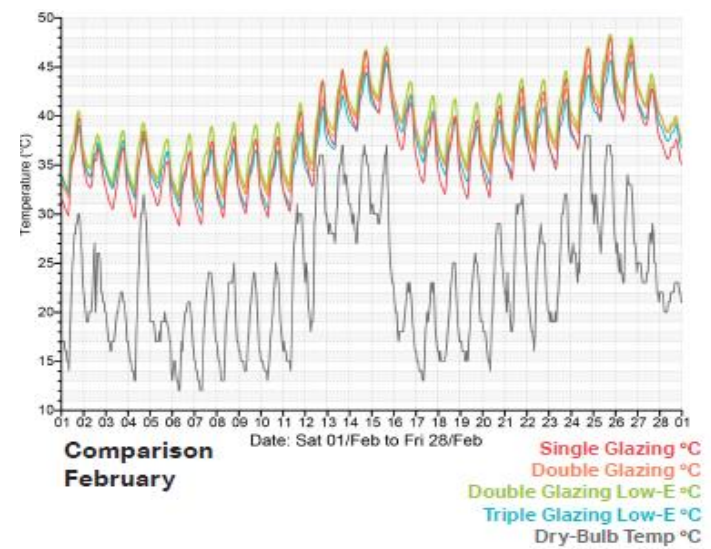

Figure 7: Predicted indoor temperatures during a summer month from using different glazing types.

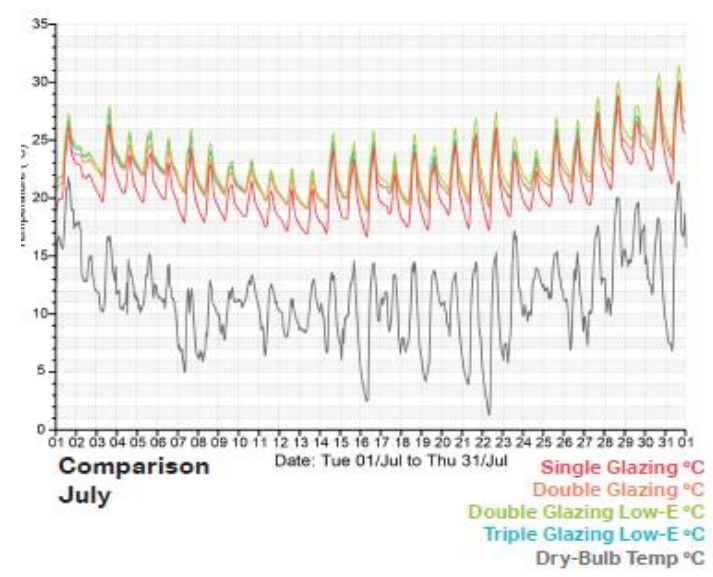

Figure 8: Predicted indoor temperatures during a winter month from using different glazing types.
The results showed that there was little difference between using double and triple glazing with argon infill (Figures 7 and 8). However, considering that the use of triple glazing in this region was uncommon and very expensive, the student decided to use double-glazing with argon infill for the next explorations.

\section{Stage 2 - Application of double skin}

In the second stage, the student tested the impact of adding another layer to the external wall, or creating a double skin façade (Figure 9) as a way to shade the windows - to reduce solar heat gain and excessive sunlight. However, before testing this, the student predicted the indoor temperatures in February if the windows were fixed/closed and if they were operable.

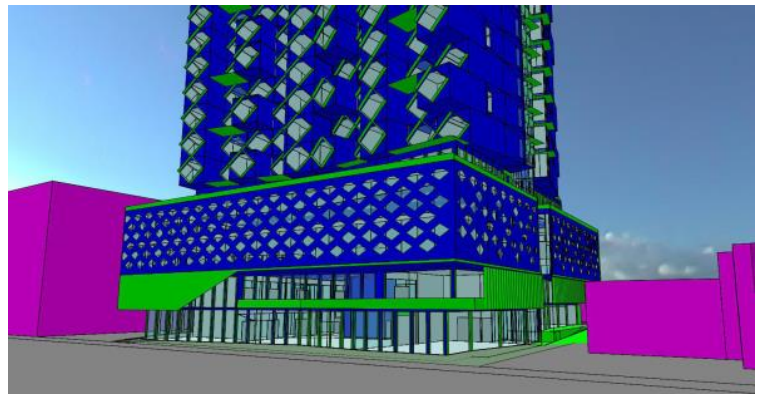

Figure 9: Applying an outer skin.
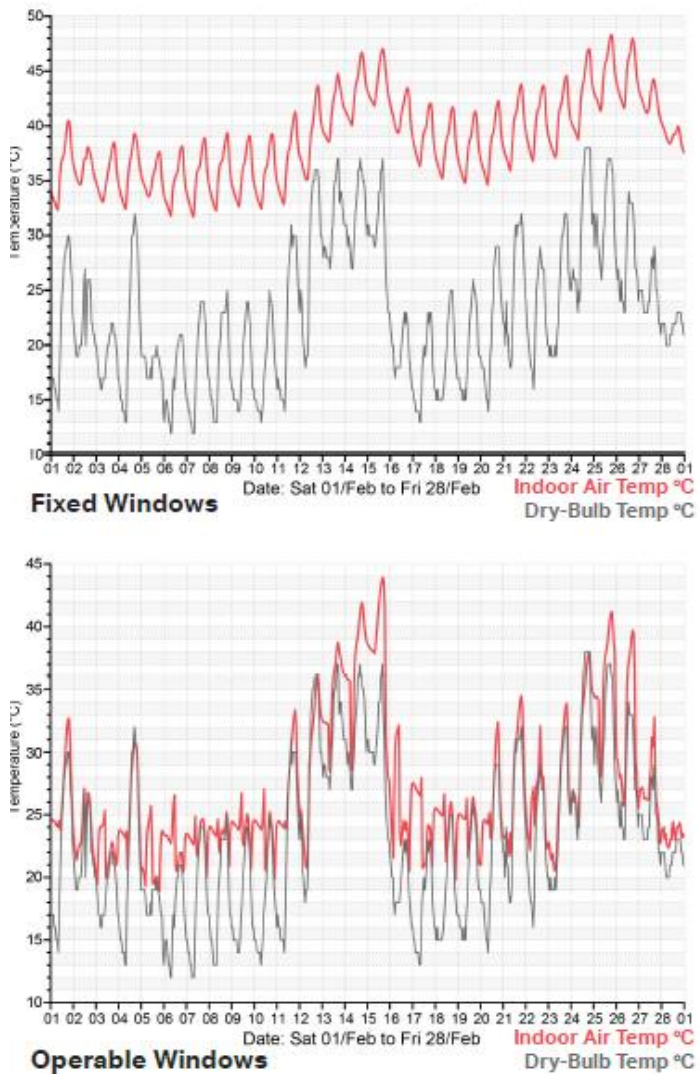

Figure 10: Predicted indoor summer temperatures with fixed windows (top) and operable windows (bottom). 
The results (Figure 10) showed that the indoor temperatures without cooling would only be within the acceptable range if the windows were operable. Opening the windows when the outdoor temperatures were below $30{ }^{\circ} \mathrm{C}$ and above $18{ }^{\circ} \mathrm{C}$ would result in relatively comfortable indoor temperatures in the summer compared to when all the windows were closed/fixed. However, there would be times during hot summer days when the indoor temperatures still exceeded $35^{\circ} \mathrm{C}$ as the outdoor temperatures reached almost $45^{\circ} \mathrm{C}$.

Following this test, an outer layer constructed of $200 \mathrm{~mm}$ glass-reinforced concrete skin was applied. The percentage of openness of the skin was $80 \%, 80 \%$ and $30 \%$ for the east, north and west façade, respectively. Applying this outer skin lowered the indoor temperatures in the summer to a more desirable level when the windows were open at the right time. During winter, the indoor temperatures were also kept at a reasonable range as long as the windows were closed (Figure 11).
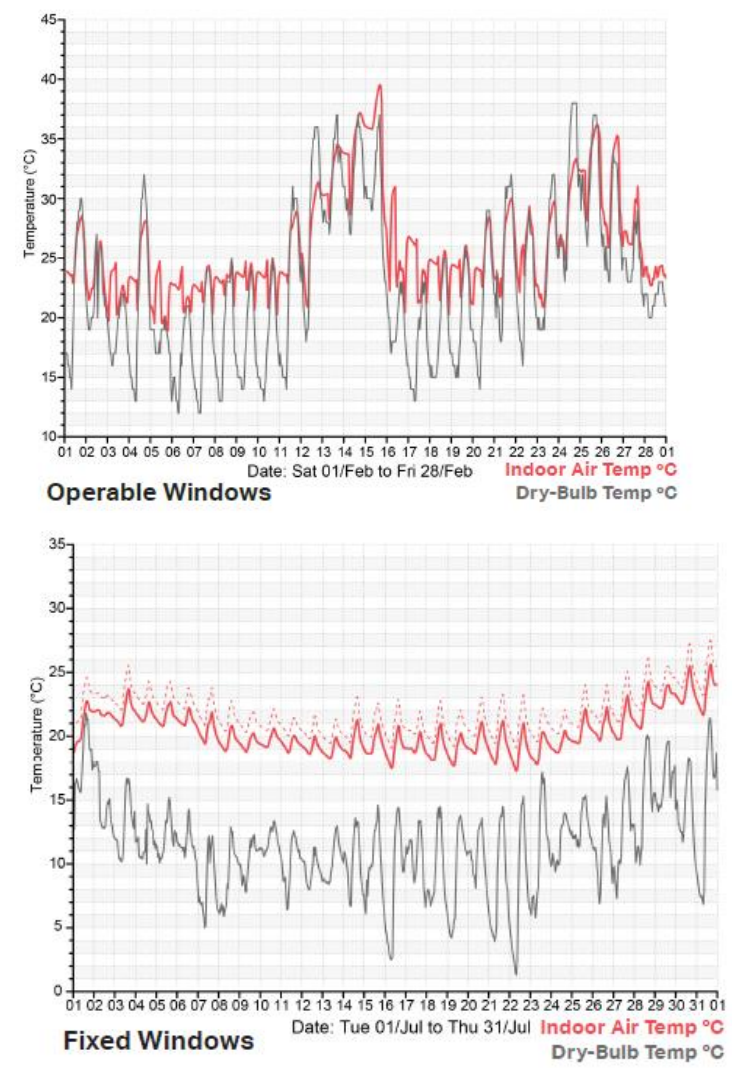

Figure 11: Predicted indoor temperatures with additional outer skin in a summer month (top) and winter month (bottom).

\section{Stage 3 - Change of wall materials}

In the final exploration, the student changed the materials of the external and internal walls focusing on one of the apartment levels. The initial external wall materials were either $200 \mathrm{~mm}$ precast concrete with plasterboard lining for the west façade $(\mathrm{U}=1.742 \mathrm{~W} / \mathrm{m} 2 . \mathrm{K})$ or insulated fibre cement sheeting on steel frames with plasterboard internal lining $(\mathrm{U}=0.447 \mathrm{~W} / \mathrm{m} 2 . \mathrm{K})$ for all other facades. The initial internal walls were plasterboards on double-steel studs with double insulation $(\mathrm{U}=0.345 \mathrm{~W} / \mathrm{m} 2 . \mathrm{K})$. The external wall materials on the west façade were then changed to $110 \mathrm{~mm}$ precast concrete with $80 \mathrm{~mm}$ insulation and rainscreen external cladding and plasterboard internal lining $(\mathrm{U}=0.9 \mathrm{~W} / \mathrm{m} 2 . \mathrm{K})$ while for the other external walls the same construction was used but with thicker insulation $(\mathrm{U}=0.413 \mathrm{~W} / \mathrm{m} 2 . \mathrm{K})$. For the internal walls, the same construction was applied but with increased insulation (total $\mathrm{U}=0.314 \mathrm{~W} / \mathrm{m} 2 . \mathrm{K}$ ).

With the improved wall materials (plus operable windows) the indoor temperatures during summer as well as winter months improved: cooler in summer and warmer in winter, as shown in Figure 12. Note that in both Figures 11 and 12, the dotted lines indicate the temperatures of the base case.
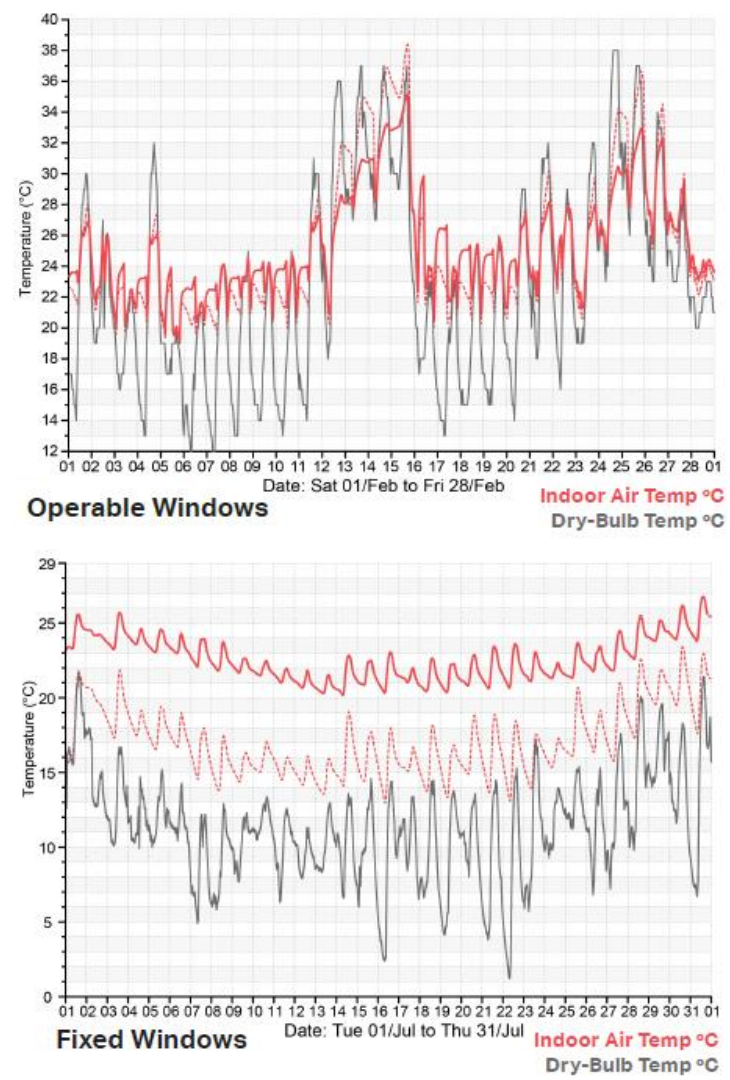

Figure 12: Predicted indoor temperatures with improved wall materials in a summer month (top) and winter month (bottom).

\section{Student Evaluation of Learning \& Teaching}

The above work is only one example of the kind of explorations that architecture students usually do in this course by using BPS software. Explorations by other students included investigating the impacts of adding an atrium on daylight penetration, illumination and brightness levels; the impacts of green roof on indoor temperatures and cooling energy; and the impact on whole-building energy use from changing various design parameters, e.g. window area, adding external shading, and changing thermostat setting.

At the end of the semester, students evaluated their learning experience in the course (not just about the use 
of BPS) through a formal student evaluation of learning and teaching conducted on-line. The evaluation was anonymous and on a 7-point Likert scale. Students also provided comments in the open-ended sections of the evaluation to indicate the positive and negative experience in the course.

Table 1 summarises the mean scores and medians of student evaluations from 55 students (maximum point of each evaluation category was 7). As can be seen in the table, students valued the use of digital activities and resources (i.e. the use of BPS). Most students indeed found BPS to be a very useful tool in understanding the impacts of design decisions on the environmental performance of the building, as shown in some of the open-ended comments, such as:

"Great practical knowledge that relates directly to the architecture industry"

"Ties in very nicely with the studio and helped me consider aspects of high-rise design that I had never considered before."

"The practical knowledge allows not only insight into how designs are meeting issues such as climate change, environmental issues and clever ways of saving energy with the use of assisted systems."

"[The best aspect of the course is] learning new software and engaging with innovation"

Table 1: Student evaluation summary.

\begin{tabular}{|l|c|c|}
\hline \multicolumn{1}{|c|}{ Evaluation } & Mean & Median \\
\hline $\begin{array}{l}\text { Satisfied with quality of the } \\
\text { course }\end{array}$ & 5.9 & 6 \\
\hline $\begin{array}{l}\text { Helps build understanding of } \\
\text { key concepts }\end{array}$ & 5.7 & 6 \\
\hline Intellectually stimulating & 6.3 & 6 \\
\hline $\begin{array}{l}\text { Includes digital activities and } \\
\text { resources that help me learn }\end{array}$ & 6.3 & 6 \\
\hline Receives useful feedback & 6 & 6 \\
\hline $\begin{array}{l}\text { Assessment tasks help me } \\
\text { learn }\end{array}$ & 5 & 6 \\
\hline $\begin{array}{l}\text { Helps to develop thinking } \\
\text { skills (problem solving \& } \\
\text { critical analysis) }\end{array}$ & 5.9 & 6 \\
\hline
\end{tabular}

Initially, we anticipated that inter-operability (for example, between this BPS software and CAD packages such as Revit, Rhino or SketchUp) would be the main issue that students would raise. While some commented that it was not easy to import a building model created in any of those CAD packages, this turned out to be not a major issue. Some students were able to convert their Revit models into the building model readable by this BPS software, though with difficulties. For the majority, they found that it was relatively much faster to model the building directly in the BPS software instead of spending time trying to redo the building model in Revit in order to make the model file readable by the BPS software. Since we provided students with templates for occupancy schedules, temperature settings, HVAC use profiles and any other relevant parameters that they could use for the base case building, based on applicable standards and common building practices, all the students needed to do after modelling the building was to place the building in the right location and apply the given templates. Thus most of their time was spent on (1) modelling the building geometry, then (2) applying the design changes, as well as (3) understanding and interpreting the results.

Nevertheless, the main criticism about the course, and indeed about the BPS-related activities, was the userfriendliness of the software itself, and the fact that, for some technical reasons, the software crashed too frequently. It appeared that the software worked perfectly on individual computers, but presented numerous problems when executed from the main server of the computer lab. Students' comments include:

"Modelling software is very one dimensional and difficult to use."

Students who used the BPS software in the computer lab (instead of using it on their own personal computer) stated:

"The state of the ... program at the Architecture School in its current state is awful. Constant crashing, awkward user interface, etc make it a battle to work with."

"The vital program in which the course is based around is completely broken."

"I found the workshops hard to keep up with due to the amount of crashing of the program and by the time I had rebooted it, I was well behind where the tutor was up to."

While the technical issues the students experienced had nothing to do with the software capabilities, the fact that these technical problems (i.e. program crashes) occurred too frequently did affect students' willingness to learn and use the BPS software, despite the fact that they saw the benefits of using it. Parallel to this was the user-interface of the software, which, for many, was perceived as too difficult to use due to a less clear structure.

\section{Discussion and Conclusion}

Even though in practice very few architects would perform BPS during the design process and the majority would leave performing BPS to the environmental consultants, our students were able to see and understand the benefits of using BPS during a design process. Unfortunately, the user-friendliness of the user-interface of the BPS program, as well as the technical issue relating to running the software from the server, was the main hindrance. The user-friendliness issues mainly relate to the structure of the user-interface, and for some students, it had to do with the modelling capabilities of the software. As part of their education, architecture students need to explore many design possibilities, including nonsimple geometry, while most BPS researchers or engineers and BPS software developers tend to model, or create BPS software to model, simpler and more straightforward building geometry.

So, while students see the power of BPS and the role it plays in a design process, the current limitations of the 
user interface and modelling capability of the BPS program continue to be a major issue and may affect their willingness to use it in their future career. This evaluation echoes the findings by Attia et al (2012) and Hopfe et al (2017) and continue to be the challenge that needs to be overcome if we want BPS to be part of architectural design processes.

One might argue that it is unnecessary for architects to perform, and thus for architecture students to learn, BPS. In practice, most architecture offices, particularly the large scale architecture firms, would either have BPS specialists within the firm (who do not necessarily have an architecture background) or outsource the task to a specialist outside the firm. This paper, however, argues that, considering that architecture students understand the role BPS plays in the design process, and so do architects in practice (Soebarto et al, 2015), if the BPS software has a clearer structure and is able to model complex building geometry, it is not impossible for architects to use BPS in practice. Architects or building designers only want to explore the impact of location-related aspects (such as building orientation, external structures), building design, envelope materials, and internal usage, on the building performance, and not detailed environmental control systems, thus it is still critical to have a BPS tool that can support the need for design explorations.

With the increasing demand by clients to have 'zero energy' or 'zero carbon' building, architects do need to perform BPS without having to rely too much on the specialist during the design process. Detailed simulation, such as for the building services systems, can then be performed during the later stages by the engineers and/or building services simulation specialists.

In summary, this paper has highlighted that architecture students do appreciate and understand the value of using BPS in a design process. As architecture students (and architects in general) like to "push the boundary" through their design, it is important that the user-interface of the BPS software has a clear structure and sufficient modelling capabilities. This will allow these building designers to explore the impact of various aspects of building design on the building performance without sacrificing the complexity of the design they would like to explore.

\section{Acknowledgement}

The author wishes to acknowledge the work by James Frolow, which has been used as an example presented in this paper.

\section{References}

Attia, S., Hensen, J.L.M., Beltran, L., De Herde, A. (2012). Selection criteria for building performance simulation tools: Contrasting architects' and engineers' needs. Journal of Building Performance Simulation, Vol 5, No 3, May 2012, 155-169.

Charles, P., Thomas, C. (2010). Integrating Building Performance Simulation in Studio teaching: a multidisciplinary consultancy based model, 98th ACSA Annual Meeting Proceedings, Rebuilding, 178-187.

Government of South Australia (2015). Carbon Neutral Adelaide Action Plan 2016-2021. Available online: http://www.climatechange.sa.gov.au/files/sharedassets/ climate_change/carbon-neutral-action-plan.pdf

Hopfe, C.J., Soebarto, V., Crawley, D., Rawal, R. (2017). Understanding the differences of integrating building performance simulation in the architectural education system. Proceedings of the 15th IBPSA Conference, San Francisco, CA, USA, Aug. 7-9, 2017, 1249-1256.

Hyun, S, Marjanovic-Halburd, L, Raslan R. (2015). Investigation into informational compatibility of Building Information Modelling and Building Performance Analysis software solutions. Building Information Modelling (BIM) in Design, Construction and Operations, WIT Transactions on The Built Environment, Vol 149: 543-553.

Rauen, C.A. (2001). Using simulation to teach critical thinking skills. You can't just throw the book at them. Critical Care Nursing Clinics North America 3(1):93103.

Reinhart, C.F, Dogan, T, Ibarra, D, Samuelson, W.H. (2012). Learning by Playing - Teaching Energy Simulation as a Game. Journal of Building Performance Simulation 5(6)(November): 359-368.

Soebarto, V., Hopfe, C.J., Crawley, C., Rawal, R. (2015). Capturing the view of architects about building performance simulation to be used during design processes. Proceedings of the 14th IBPSA Conference, Hyderabad, India, Dec. 7-9, 2017, 1480-1487. 